\title{
Targeting the endocannabinoid system to treat haunting traumatic memories
}

\author{
Irit Akirav* \\ Department of Psychology, University of Haifa, Haifa, Israel \\ *Correspondence: irit.akirav@gmail.com \\ Edited by: \\ Benno Roozendaal, University Medical Center Groningen, Netherlands \\ Reviewed by: \\ Piray Atsak, Radboud University Nijmegen Medical Centre, Netherlands
}

Keywords: endocannabinoids, memory, PTSD rat, anxiety disorders, extinction learning

\section{A commentary on}

The endocannabinoid system as a possible target to treat both the cognitive and emotional features of post-traumatic stress disorder (PTSD)

by Trezza, V., and Campolongo, P. (2013).

Front. Behav. Neurosci. 7:100. doi: 10.3389/

fnbeh.2013.00100

One of the core symptoms in posttraumatic stress disorder (PTSD) is the traumatic memory that constantly haunts the patient. PTSD is a paradoxical disorder of memory-on the one hand, intrusive recollections for certain aspects of the event and, on the other hand, amnesia for other important aspects (Ehlers et al., 2004). Intrusive memories, often triggered automatically by situations that reflect aspects of the traumatic event, are accompanied by high levels of arousal and might be experienced as "flashbacks" (vanOyen Witvliet, 1997).

A major question in studying PTSD is how can an external traumatic event impact on the biology of the organism to produce such durable memory traces of that event that are so highly resistant to extinction? (Pitman, 1989).

An increasing body of evidence points to the endocannabinoid $(\mathrm{eCB})$ system as a key system in the regulation of emotionality and memory (Haller et al., 2002, 2004; Marsicano et al., 2002; Lutz, 2007; GanonElazar and Akirav, 2009; Abush and Akirav, 2010; Moreira and Wotjak, 2010; Parolaro et al., 2010; Atsak et al., 2012b; Ganon-Elazar and Akirav, 2012, 2013; Abush and Akirav, 2013; Campolongo et al., 2013). Hence, eCB enhancers may be the ideal pharmacological treatment for
PTSD by blocking the pathological over consolidation and continuous retrieval of the traumatic event on the one hand, and enhancing its extinction and reducing the anxiety symptoms on the other hand. These effects fit well with the concept of reducing fear memory.

These ideas were recently published in an interesting and highly relevant perspective by Trezza and Campolongo. The authors suggested the eCB system as a possible pharmacological treatment that modulates the consolidation, retrieval and extinction of these durable memory traces. Together with the effects of eCB on stress and anxiety, the whole PTSD spectrum is addressed.

The authors reviewed the literature suggesting that eCBs have an essential role in maintaining emotional homeostasis (Haller et al., 2002, 2004; Lutz, 2007; Niyuhire et al., 2007; Hill and Gorzalka, 2009; Moreira and Wotjak, 2010; Parolaro et al., 2010) and in modulating memory consolidation, retrieval and extinction (Marsicano et al., 2002; Niyuhire et al., 2007; Marsicano and Lafenetre, 2009; Atsak et al., 2012a; Campolongo et al., 2013). Specifically, cannabinoids strongly facilitate memory extinction in animals (Marsicano et al., 2002; Lutz, 2007; Abush and Akirav, 2010), while impairing memory retrieval (Niyuhire et al., 2007; Atsak et al., 2012a). Regarding the effects of cannabinoids on memory consolidation for emotionally salient events, they reported controversial results from preclinical studies. On the one hand, post-training administration of cannabinoid receptor direct or indirect agonists facilitated memory consolidation in the inhibitory avoidance task (Campolongo et al., 2009; Hauer et al., 2011). However, other studies suggested that cannabinoid agonists administered to rats shortly after exposure to a series of intense stressful events prevented PTSD-like symptoms (Ganon-Elazar and Akirav, 2012, 2013).

Hence, the authors concluded that eCBs could be an ideal drug to treat PTSD by addressing both the emotional and cognitive aspects of the disorder. Yet, attention needs to be dedicated to the time framing of pharmacological treatment, with an attempt to avoid the first early phases of memory consolidation.

Indeed, accumulating data from both clinical and pre-clinical studies suggest that targeting the eCB system may benefit PTSD. Given the similarities between extinction procedures and exposure-based psychotherapy used for the treatment of fear disorders in humans (Myers and Davis, 2007), the eCB system represents a novel pharmacological target for anxiety disorders related to inappropriate retention of aversive memories (Marsicano et al., 2002; Chhatwal et al., 2005; Bitencourt et al., 2008). Accordingly, human studies suggest that cannabinoids may be used as an adjunct to extinctionbased therapies for anxiety disorders. In support, Rabinak et al. (2013) found that subjects that received $\Delta^{9}$-THC showed enhanced extinction memory and Das et al. (2013) showed a similar effect using the agonist cannabidiol.

A recent study with rats suggested that predator exposure causes longlasting anxiogenic effects associated with hyperactivation of amygdaloid complex and modulation of $\mathrm{CB} 1$ receptor in brain areas related to PTSD symptoms (Campos et al., 2013). Seven days 
after predator threat rats showed lasting anxiogenic effects and CB1 mRNA expression was down regulated in the frontal cortex and amygdaloid complex (Campos et al., 2013). Studies in humans also suggested alterations in the eCB system in PTSD. Hauer et al. (2013) indicated that individuals with PTSD show significant differences in plasma concentrations of eCBs and related $\mathrm{N}$ acyl-ethanolamides when compared to healthy controls and to subjects after trauma exposure who did not develop PTSD. Neumeister et al. (2013) reported that PTSD patients demonstrated elevated brain cannabinoid $\mathrm{CB} 1$ receptor availability and suggested that abnormal CB1 receptor-mediated anandamide signaling is implicated in the etiology of PTSD. Moreover, it has been suggested that higher CB1 receptor density in women than men under basal (i.e., nonstress) conditions may explain the epidemiological literature consistently reporting gender differences in PTSD. Hence, higher CB1 receptor density in women may be a risk factor to developing PTSD after trauma (Neumeister, 2013).

Cannabinoid agonists administered shortly after exposure to an intense stressful event (i.e., exposure to $2 \mathrm{~h}$ restraint followed by forced swim and sedation or exposure to predator stress) can prevent the development of PTSDlike symptoms in rats (Campos et al., 2012; Ganon-Elazar and Akirav, 2012, 2013), suggesting that eCB enhancers may be beneficial in PTSD. Indeed, two open label clinical trials demonstrated potential benefits of cannabis in patients with PTSD. Fraser (2009) found that the synthetic cannabinoid nabilone significantly improved treatment-resistant nightmares in PTSD patients. Shalev's (Shalev et al., 2013) group reported that 10 outpatients with chronic PTSD that received $\Delta^{9}$-THC twice a day for 3 weeks demonstrated a significant improvement in arousal, sleep quality and nightmares.

Several studies support the selfmedication hypothesis explanation for cannabis use to cope with PTSD symptoms (Cougle et al., 2011; Passie et al., 2012). Others reported a strong correlation between PTSD symptom severity and the amount of cannabis use (Bonn-Miller et al., 2011; Cougle et al., 2011; Potter et al., 2011). Moreover, the starting point of using cannabis correlated with the onset of PTSD symptoms (Cougle et al., 2011) suggesting that cannabis use was used to help reduce aversive mood states.

To conclude, the eCB system may be a useful target for treating both the cognitive and emotional features of PTSD, but more research is needed in order to recognize and avoid the circumstances under which a pharmacological treatment with eCB agents might have a deleterious effect on behavior.

\section{REFERENCES}

Abush, H., and Akirav, I. (2010). Cannabinoids modulate hippocampal memory and plasticity. Hippocampus 20, 1126-1138. doi: 10.1002/hipo.20711

Abush, H., and Akirav, I. (2013). Cannabinoids ameliorate impairments induced by chronic stress to synaptic plasticity and short-term memory. Neuropsychopharmacology 38, 521-534. doi: 10.1038/npp.2013.51

Atsak, P., Hauer, D., Campolongo, P., Schelling, G., McGaugh, J. L., and Roozendaal, B. (2012a). Glucocorticoids interact with the hippocampal endocannabinoid system in impairing retrieval of contextual fear memory. Proc. Natl. Acad. Sci. U.S.A. 109, 3504-3509. doi: 10.1073/pnas.1200742109

Atsak, P., Roozendaal, B., and Campolongo, P. (2012b). Role of the endocannabinoid system in regulating glucocorticoid effects on memory for emotional experiences. Neuroscience 204, 104-116. doi: 10.1016/j.neuroscience.2011.08.047

Bitencourt, R. M., Pamplona, F. A., and Takahashi, R. N. (2008). Facilitation of contextual fear memory extinction and anti-anxiogenic effects of AM404 and cannabidiol in conditioned rats. Eur. Neuropsychopharmacol. 18, 849-859. doi: 10.1016/j.euroneuro.2008.07.001

Bonn-Miller, M. O., Vujanovic, A. A., and Drescher, K. D. (2011).Cannabis use among military veterans after residential treatment for posttraumatic stress disorder. Psychol. Addict. Behav. 25, 485-491. doi: 10.1037/a0021945

Campolongo, P., Morena, M., Scaccianoce, S., Trezza, V., Chiarotti, F., Schelling, G., et al. (2013). Novelty-induced emotional arousal modulates cannabinoid effects on recognition memory and adrenocortical activity. Neuropsychopharmacology 38, 1276-1286. doi: 10.1038/npp.2013.26

Campolongo, P., Roozendaal, B., Trezza, V., Hauer, D., Schelling, G., McGaugh, J. L., et al. (2009). Endocannabinoids in the rat basolateral amygdala enhance memory consolidation and enable glucocorticoid modulation of memory. Proc. Natl. Acad. Sci. U.S.A. 106, 4888-4893. doi: 10.1073/pnas.0900835106

Campos, A. C., Ferreira, F. R., da Silva, W. A. Jr., and Guimarães, F. S. (2013). Predator threat stress promotes long lasting anxiety-like behaviors and modulates synaptophysin and CB1 receptors expression in brain areas associated with
PTSD symptoms. Neurosci. Lett. 533, 34-38. doi: 10.1016/j.neulet.2012.11.016

Campos, A. C., Ferreira, F. R., and Guimarães, F. S. (2012). Cannabidiol blocks long-lasting behavioral consequences of predator threat stress: possible involvement of 5HT1A receptors. J. Psychiatr. Res. 46, 1501-1510. doi: 10.1016/j.jpsychires.2012.08.012

Chhatwal, J. P., Davis, M., Maguschak, K. A., and Ressler, K. J. (2005). Enhancing cannabinoid neurotransmission augments the extinction of conditioned fear. Neuropsychopharmacology 30, 516-524. doi: 10.1038/sj.npp.1300655

Cougle, J. R., Bonn-Miller, M. O., Vujanovic, A. A., Zvolensky, M. J., and Hawkins, K. A. (2011). Posttraumatic stress disorder and cannabis use in a nationally representative sample. Psychol. Addict. Behav. 25, 554-558. doi: 10.1037/a0023076

Das, R. K., Kamboj, S. K., Ramadas, M., Yogan, K., Gupta, V., Redman, E., et al. (2013). Cannabidiol enhances consolidation of explicit fear extinction in humans. Psychopharmacology (Berl.) 226, 781-792. doi: 10.1007/s00213-012-2955-y

Ehlers, A., Hackmann, A., and Michael, T (2004). Intrusive re-experiencing in posttraumatic stress disorder: phenomenology, theory, and therapy. Memory 12, 403-415. doi: 10.1080/09658210444000025

Fraser, G. A. (2009). The use of a synthetic cannabinoid in the management of treatmentresistant nightmares in posttraumatic stress disorder (PTSD). CNS Neurosci. Ther. 15, 84-88. doi: 10.1111/j.1755-5949.2008.00071.x

Ganon-Elazar, E., and Akirav, I. (2009). Cannabinoid receptor activation in the basolateral amygdala blocks the effects of stress on the conditioning and extinction of inhibitory avoidance. J. Neurosci. 29, 11078-11088. doi: 10.1523/JNEUROSCI.122309.2009

Ganon-Elazar, E., and Akirav, I. (2012). Cannabinoids prevent the development of behavioral and endocrine alterations in a rat model of intense stress. Neuropsychopharmacology 37, 456-466. doi: 10.1038/npp.2011.204

Ganon-Elazar, E., and Akirav, I. (2013). Cannabinoids and traumatic stress modulation of contextual fear extinction and GR expression in the amygdala-hippocampalprefrontal circuit. Psychoneuroendocrinology doi: 10.1016/j.psyneuen.2013.01.014. [Epub ahead of print].

Haller, J., Bakos, N., Szirmay, M., Ledent, C., and Freund, T. F. (2002). The effects of genetic and pharmacological blockade of the CB1 cannabinoid receptor on anxiety. Eur. J. Neurosci. 16, 1395-1398. doi: 10.1046/j.1460-9568.2002.02192.x

Haller, J., Varga, B., Ledent, C., Barna, I., and Freund, T. F. (2004). Context-dependent effects of CB1 cannabinoid gene disruption on anxietylike and social behaviour in mice. Eur. J. Neurosci. 19, 1906-1912. doi: 10.1111/j.14609568.2004.03293.x

Hauer, D., Ratano, P., Morena, M., Scaccianoce, S., Briegel, I., Palmery, M., et al. (2011). Propofol enhances memory formation via an interaction with the endocannabinoid system. Anesthesiology 114, 1380-1388. doi: 10.1097/ALN.0b013e31821c120e 
Hauer, D., Schelling, G., Gola, H., Campolongo, P., Morath, J., Roozendaal, B., et al. (2013). Plasma concentrations of endocannabinoids and related primary fatty acid amides in patients with posttraumatic stress disorder. PLoS ONE 8:e62741. doi: 10.1371/journal.pone.0062741

Hill, M. N., and Gorzalka, B. B. (2009). The endocannabinoid system and the treatment of mood and anxiety disorders. CNS Neurol. Disord. Drug Targets 8, 451-458. doi: $10.2174 / 187152709789824624$

Lutz, B. (2007). The endocannabinoid system and extinction learning. Mol. Neurobiol. 36, 92-101. doi: 10.1007/s12035-007-8004-x

Marsicano, G., and Lafenetre, P. (2009). Roles of the endocannabinoid system in learning and memory. Curr. Top. Behav. Neurosci. 1, 201-230. doi: 10.1007/978-3-540-88955-7_8

Marsicano, G., Wotjak, C. T., Azad, S. C., Bisogno, T., Rammes, G., Cascio, M. G., et al. (2002). The endogenous cannabinoid system controls extinction of aversive memories. Nature 418, 530-534. doi: 10.1038/nature00839

Moreira, F. A., and Wotjak, C. T. (2010). Cannabinoids and anxiety. Curr. Top. Behav. Neurosci. 2, 429-450. doi: 10.1007/7854_2009_16

Myers, K. M., and Davis, M. (2007). Mechanisms of fear extinction. Mol. Psychiatry 12, 120-150. doi: 10.1038/si.mp.4001939

Neumeister, A. (2013). The endocannabinoid system provides an avenue for evidence-based treatment development for PTSD. Depress. Anxiety 30, 93-96. doi: $10.1002 / \mathrm{da} .22031$
Neumeister, A., Normandin, M. D., Pietrzak, R. H., Piomelli, D., Zheng, M. Q., Gujarro-Anton, A., et al. (2013). Elevated brain cannabinoid CB1 receptor availability in post-traumatic stress disorder: a positron emission tomography study. Mol. Psychiatry 18, 1034-1040. doi: 10.1038/mp. 2013.61

Niyuhire, F., Varvel, S. A., Martin, B. R., and Lichtman, A. H. (2007). Exposure to marijuana smoke impairs memory retrieval in mice. J. Pharmacol. Exp. Ther. 322, 1067-1075. doi: 10.1124/jpet.107.119594

Parolaro, D., Realini, N., Vigano, D., Guidali, C., and Rubino, T. (2010). The endocannabinoid system and psychiatric disorders. Exp. Neurol. 224, 3-14. doi: 10.1016/j.expneurol.2010.03.018

Passie, T., Emrich, H. M., Karst, M., Brandt, S. D., and Halpern, J. H. (2012). Mitigation of posttraumatic stress symptoms by Cannabis resin: a review of the clinical and neurobiological evidence. Drug Test. Anal. 4, 649-659. doi: 10.1002/ dta. 1377

Pitman, R. K. (1989). Post-traumatic stress disorder, hormones, and memory. Biol. Psychiatry 26, 221-223. doi: 10.1016/0006-3223(89)90033-4

Potter, C. M., Vujanovic, A. A., Marshall-Berenz, E. C., Bernstein, A., and Bonn-Miller, M. O. (2011). Posttraumatic stress and marijuana use coping motives: the mediating role of distress tolerance. J. Anxiety Disord. 25, 437-443. doi: 10.1016/j.janxdis.2010.11.007

Rabinak, C. A., Angstadt, M., Sripada, C. S., Abelson, J. L., Liberzon, I., Milad, M. R., et al.
(2013). Cannabinoid facilitation of fear extinction memory recall in humans. Neuropharmacology 64, 396-402. doi: 10.1016/j.neuropharm.2012. 06.063

Shalev, A. Roitman, P., and Mechoulam, R. (2013). "Pilot open label trial on oral absorbable $\Delta^{9}$-THC for chronic PTSD," in Israel Society for Biological Psychiatry abstract book, Hagoshrim, Israel.

vanOyen Witvliet, C. (1997). Traumatic intrusive imagery as an emotional memory phenomenon: a review of research and explanatory information processing theories. Clin. Psychol. Rev. 17, 509-536. doi: 10.1016/S0272-7358(97) 00025-1

Received: 17 August 2013; accepted: 02 September 2013; published online: 19 September 2013.

Citation: Akirav I (2013) Targeting the endocannabinoid system to treat haunting traumatic memories. Front. Behav. Neurosci. 7:124. doi: 10.3389/fnbeh. 2013.00124

This article was submitted to the journal Frontiers in Behavioral Neuroscience.

Copyright (c) 2013 Akirav. This is an open-access article distributed under the terms of the Creative Commons Attribution License (CC BY). The use, distribution or reproduction in other forums is permitted, provided the original author(s) or licensor are credited and that the original publication in this journal is cited, in accordance with accepted academic practice. No use, distribution or reproduction is permitted which does not comply with these terms. 